\title{
Pediatric Intraparotid Neurofibroma: Rare Entity
}

\begin{abstract}
Aim: This case report provide an awareness of intraparotid facial nerve neurofibroma as a cause of parotid masses and to describe their characteristics and management considerations. Material: It is a case report of a pediatric patients with intraparotid facial nerve neurofibromas which is a rare entity. Method: It was preoperatively diagnosed as intraparotid benign tumor likely to be pleopmorphic features on fine needle aspiration cytology.Tumors arising from the extratemporal course of the facial nerve are quite rare. The tumors arise from Schwann cells and include the schwannoma and the neurofibroma. Conclusion: The overwhelming benign nature of these lesions necessitates a conservative course of treatment. Histological diagnosis should be followed by a limited tumor excision with emphasis on retaining normal facial nerve function. Malignant lesions require wide excision with facial nerve grafting or facial nerve reanimation.
\end{abstract}

Keywords: Intraparotid, neurofibroma, schwannomas

\section{Introduction}

Solitary neurofibroma of the facial nerve is generally uncommon, and most cases affect the intracranial and intratemporal parts. Intraparotid neurofibromas of the facial nerve are extremely rare and mostly associated with neurofibromatosis type 1 (NF1). In this current study, a case of solitary neurofibroma of the parotid part of the facial nerve in a man without NF1was reported.

Preoperative diagnosis of facial nerve neurofibromas in the parotid gland is generally difficult because of the low frequency of the disease and the few typical signs associated with it. The most common presenting symptom is a painless slow-growing parotid mass. The estimated incidence of parotid tumors of facial nerve origin ranges from $0.2 \%$ to $1.5 \%,{ }^{[1]}$ with $3.9 \%$ of these tumors finally diagnosed as malignant. ${ }^{[2]}$

Fine needle aspiration cytology (FNAC) and even incisional biopsy can fail to provide a correct diagnosis. Sullivan et al. noted that neurogenic neoplasms of the intraparotid facial nerve are usually only diagnosed intraoperatively by tissue biopsy. Nerve preservation during removal of neurofibroma is difficult, and nerve reconstruction is usually needed either by

This is an open access article distributed under the terms of the Creative Commons Attribution-NonCommercial-ShareAlike 3.0 License, which allows others to remix, tweak, and build upon the work non-commercially, as long as the author is credited and the new creations are licensed under the identical terms.

For reprints contact: reprints@medknow.com end-to-end anastomosis, nerve grafts, or nerve transfer. ${ }^{[3]}$

Rarity of this tumor precludes its inclusion in the differential diagnosis of benign parotid tumors at the provisional diagnosis stage. Preoperative diagnosis is extremely difficult due to the variation in clinical presentation and its dependency on the nerve site involved. Almost half of the intraparotid neurofibromas involve the main trunk of the facial nerve and usually present as a painful or painless parotid mass of long-standing duration with or without facial paresis, paralysis, or spasm. ${ }^{[3]}$ Such a presentation is similar to any other benign parotid tumor making it difficult to diagnose solitary neurofibromas at the clinical stage. Radiological findings of intraparotid neurofibromas are contributory only to the diagnosis of a benign parotid tumor. Sectional imaging helps to determine the extent of the tumor. Recently, a case of solitary neurofibroma involving the whole facial nerve continuously from geniculate ganglion to parotid segment has been reported. ${ }^{[4]}$ The main basis of diagnosis of neurofibroma is histopathological investigations. These tumors present a challenge because of their risk of malignant transformation and their high probability of operative facial nerve compromise.

We present a case which was diagnosed preoperatively as benign parotid tumor

How to cite this article: Chavan SS, Nagpure PS, Ganeshkar R. Pediatric intraparotid neurofibroma: Rare entity. Indian J Med Paediatr Oncol 2018;39:203-5.

\section{Sushil Suresh Chavan, Prakash S Nagpure, Ravi Ganeshkar}

Department of ENT, MGIMS, Wardha, Maharashtra, India
Address for correspondence: Dr. Sushil Suresh Chavan, Department of ENT, MGIMS, Sewagram, Wardha - 442 102, Maharashtra, India.

E-mail:drsushilschavan2111@ gmail.com

Access this article online

Website: www.ijmpo.org

DOI: 10.4103/ijmpo.ijmpo_130_17 Quick Response Code:

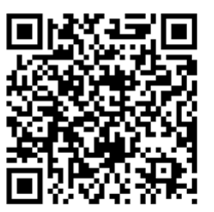




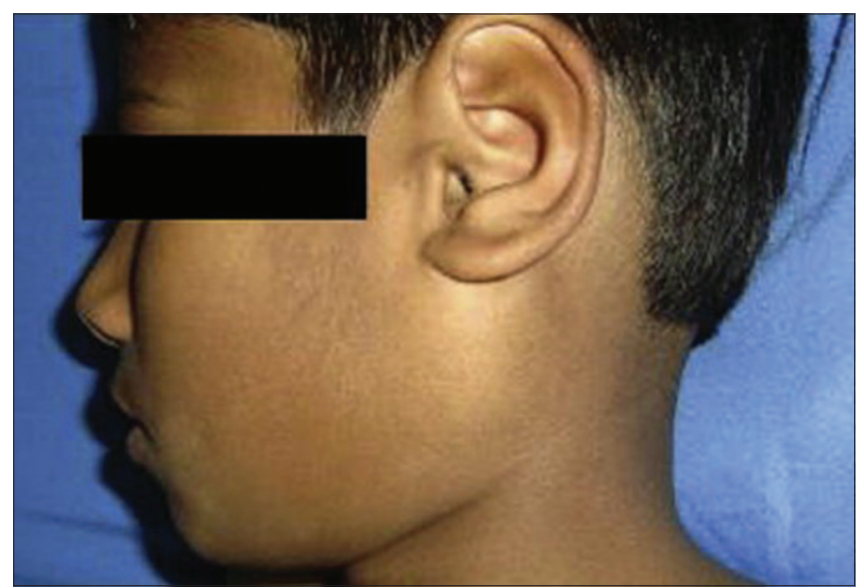

Figure 1: Preoperative image of the patient

and found to be neurofibroma after surgical excision and histopathological examination. The diagnostic problems, the biological behavior, and therapeutic management of this infrequent tumor entity are discussed.

\section{Case Report}

A healthy 5-year-old child presented with a painless left infra-auricular swelling, which had been present for about 2 years [Figure 1]. Clinical examination revealed an oval, firm, nontender mass, which was not adherent to the overlying skin in the left parotid gland region and which showed normal facial nerve function. No other abnormality was detected in the patient. FNAC revealed a benign lesion with pleomorphic features. The lesion was considered as a benign parotid gland lesion. During surgery and after identifi cation of the main trunk of the facial nerve, the superfi cial part of the parotid gland was started to be removed. A single large mass of $6 \mathrm{~cm} \times 3 \mathrm{~cm}$ incorporating the upper division of the facial nerve was observed. After removal of the superfi cial part of the parotid gland, a large mass incorporating the superior division of the facial nerve was observed [Figure 2]. Dissection of the mass from the facial nerve failed, so the nerve portion, which was involved in the mass (buccal branch of the facial nerve), was inevitably sacrifi ced. The fi nal histopathology revealed a neurofi broma of the facial nerve. Incomplete left side facial nerve paralysis was observed immediately postoperatively.

Histopathological examination showed proliferation of all elements of nerve which include axons, Schwann cells, and fi broblasts. ${ }^{[5]}$ Neurofi bromas are characterized by relatively scant, haphazard arrangement of delicate spindle cells among a loosely textured collagenous matrix and may also incorporate nerve fi bers within the tumor.

\section{Discussion}

Primary neurogenic tumors of the facial nerve are uncommon and these tumors, which arise from Schwann cells, include the more common schwannoma while

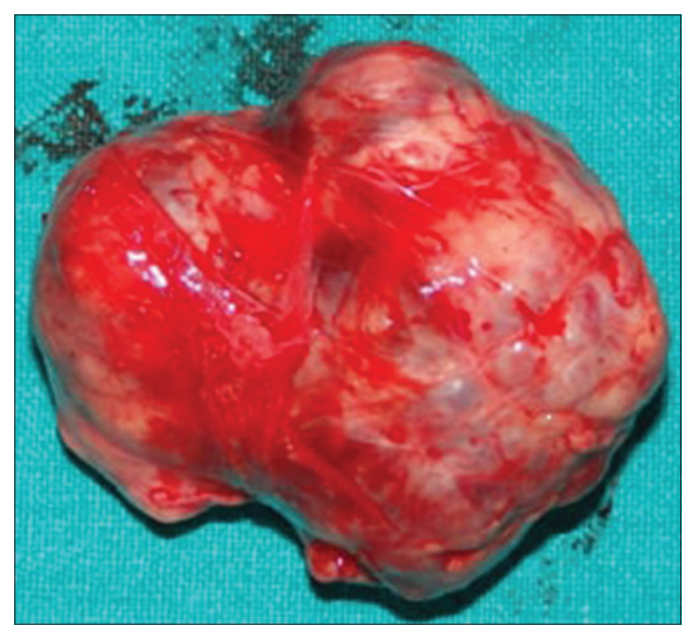

Figure 2: Post-operated specimen of left parotid gland

the exceedingly rare neurofibroma mostly affects the intratemporal part compared to the intracranial and intraparotid parts, which are much less affected. ${ }^{[6]}$

Neurofibromas may occur most commonly as a part of Von Recklinghausen's disease (NF1), ${ }^{[7]}$ which is a relatively common genetic disorder that is inherited in an autosomal dominant pattern with a wide range of expression. The major features of NF1 include multiple neural tumors, "café au lait" spots, and Lisch nodules. ${ }^{[8]}$ The case reported in this current study was single without any detected NF1 features.

Malignant transformation of neurofibromas is uncommon. Malignant transformation has been reported in $10 \%-15 \%$ of plexiform neurofibromas, but it is more common in patients whose neurofibromas arise in the setting of NF1 and patients with deeply seated neurofibromas. ${ }^{[9-11]}$

Intraparotid neurogenic neoplasm is difficult to be diagnosed correctly preoperatively. ${ }^{[12,13]}$ This was the condition present in this case as no preoperative diagnosis was made but rather an intraoperative suggestion from relation to facial nerve was made and proven through postoperative histopathological examination.

Management of neurogenic tumors of the intraparotid facial nerve is controversial unlike schwannomas which tend to displace nerves and thus allow nerve preservation. Neurofibromas, however, incorporate the nerves and are generally resected en bloc with the involved nerve. ${ }^{[14]}$ Therefore, in this case, neurofibroma was removed completely with the involved nerve with successful immediate nerve repair.

\section{Conclusion}

Neurofibroma should be considered as the diagnosis in a patient with a parotid mass even with benign preoperative criteria on examination, computed tomography, and FNAC. We believe that every effort should be done preoperatively 
to diagnose it properly. However, in cases in which diagnosis is performed intraoperatively, excision of part of the nerve with the mass will be inevitable; however, immediate repair of the facial nerve could be accomplished by end-to-end anastomosis with good recovery of function during the course of follow-up.

\section{Consent}

Informed consent was obtained from participant included in the study.

\section{Declaration of patient consent}

The authors certify that $\mathrm{i}$ have obtained all appropriate patient consent forms. In the form, the patient's parents have given consent for images and other clinical information to be reported in the journal. The patient's parents also understand that name and initials might be published with such information.

\section{Financial support and sponsorship}

Nil.

\section{Conflicts of interest}

There are no conflicts of interest.

\section{References}

1. Chiang CW, Chang YL, Lou PJ. Multicentricity of intraparotid facial nerve schwannomas. Ann Otol Rhinol Laryngol 2001;110:871-4.

2. Marchioni D, Alicandri Ciufelli M, Presutti L. Intraparotid facial nerve schwannoma: Literature review and classification proposal. J Laryngol Otol 2007;121:707-12.

3. Sullivan MJ, Babyak JW, Kartush JM. Intraparotid facial nerve neurofibroma. Laryngoscope 1987;97:219-23.

4. Yilmaz F, Gurel K, Gurel S, Sessiz N, Boran C. Geniculo-temporo-parotideal neurofibroma of the facial nerve. A case report. Neuroradiol J 2007;19:792-7.

5. Bretlau P, Melchiors H, Krogdahl A. Intraparotid neurilemmoma. Acta Otolaryngol 1983;95:382-4.

6. Pulec JL. Symposium on ear surgery II Facial nerve neuroma. Laryngoscope 1972;82:1160-76.

7. Kavanagh KT, Panje WR. Neurogenic neoplasms of the seventh cranial nerve presenting as a parotid mass. Am J Otolaryngol 1982;3:53-6.

8. Gutmann DH, Collins FS. The neurofibromatosis type 1 gene and its protein product, neurofibromin. Neuron 1993;10:335-43.

9. McGuirt WF Sr., Johnson PE, McGuirt WT. Intraparotid facial nerve neurofibromas. Laryngoscope 2003;113:82-4.

10. Prasad S, Myers EN, Kamerer DB, Demetris AJ. Neurilemmoma (schwannoma) of the facial nerve presenting as a parotid mass. Otolaryngol Head Neck Surg 1993;108:76-9.

11. Kumar BN, Walsh RM, Walter NM, Tse A, Little JT. Intraparotid facial nerve schwannoma in a child. J Laryngol Otol 1996;110:1169-70.

12. Sellars SL. Neurofibroma of the facial nerve. S Afr Med J 1972;46:1332-4.

13. Saleh E, Achilli V, Naguib M, Taibah AK, Russo A, Sanna M, et al. Facial nerve neuromas: Diagnosis and management. Am J Otol 1995;16:521-6.

14. Kumar A, Ranjan R, Kumar S, Radder S, Rana RS, Bhagat S. Intra-parotid neurofibroma of facial nerve: A case report. Int $\mathrm{J}$ Med Res Health Sci 2013;2:716-8. 